\title{
Class Structures in the Creative Industries: An Analysis of the Working Conditions of Workers in Nigeria's Fashion Sector
}

\author{
Ijeoma Onyeator \\ School of Media and Communication, Pan-Atlantic University, KM 52, Lekki- Epe Express way, Ibeju-Lekki, \\ Lagos, Nigeria
}

\begin{abstract}
Since the showcasing of indigenous designs on the world's most prestigious runways, Nigeria's fashion industry has received global endorsement and experienced rapid growth, making it a major contributor to the creative economy. Research often focuses on the success of big designers as a yardstick to measure the contribution of this sector to the wider economy. This study finds that data on the earning potential of the fashion industry is incomplete without a reflection of the contributions of the generality of creative workers found in the informal sector of the economy. It draws on interviews and direct observation of selected workers found in the production rooms of fashion houses and garment factories in Nigeria. Findings indicate that the industry is plagued by class distinctions in the work force which impedes the mapping of its true earning potential.
\end{abstract}

Keywords: creative industries, creative workers, creative labour, fashion, class structures, Nigeria's fashion sector

DOI: $10.7176 /$ RHSS/9-4-01

\section{INTRODUCTION}

There is little agreement among scholars regarding the definition of the creative industries and definitional debates still get a lot of space in academic research regarding its origin and scope. The cultural industries are the fore runners of the creative industries, and for this reason definitions often overlap, leading some scholars to believe that the two terms can be used interchangeably. One definition that has received much scrutiny conceptualizes the creative industries as activities which effectively blend culture, skill, creativity and industry (DCMS, 1998). This characterization is heavily criticized by proponents of the cultural industries who emphasize the role of culture over creativity in the production of creative products for economic value (Pratt, 2005). They believe that merging 'culture' and 'commerce' in one definition has a shock value (Adorno \& Horkheimer, 1944). Others argue that the goal of governments should be to fuse both cultural and creative arts into a lucrative economic policy agenda (Howkins, 2001; Galloway \&

Dunlop, 2007). While conceptualizations vary, there is some agreement among scholars as to the composition of the creative industries - that which concerns culture, arts and crafts as well as others such as architecture, design, film and video, interactive leisure software, the performing arts, publishing, software and computing services, advertising, music, television and radio (Flew, 2002).

However, the global concept of the creative industries was first elaborated by the Department of Culture, Media and Sport, and it was conceptualized to include those industries that not only require creativity and skill, as well as those which have the capacity to create wealth and jobs (DCMS, 2001). While this description appears comprehensive, it does not consider the argument that creative and cultural industries are marked by significant inequalities globally (Brook et al., 2018). These include but are not limited to the social class background of the workforce, and how this intersects with other issues, including discrimination, exploitation, poor wages and low productivity. This narrative of inequality in creative occupations is a cause for concern and the research interest in the present work. This experience is most evident in developing countries that have adopted the concept of the creative industries for its favorable economic benefits. One of such promises is the idea that the fusion of culture and creativity into 'creative products' can boost the economic fortunes of a country. This idea has been the goal of the Nigerian government since 2011 (NESG, 2011). Yet in comparison to other sectors of the economy, the creative sector still has a relatively low profile.

\subsection{The Peculiarities of Nigeria's Creative Industries}

Following reports of international success, many governments around the world recognize the creative industries and its sectors as key ingredients for the accomplishment of their national economic plans. The overarching idea is that adopters of the concept could transform their economies financially and reposition their countries for increased trade and investment on the world stage. Early adopters like the United Kingdom have been so successful that the creative economy is the main driver of the UK economy (British Council, 2017). Nigeria has also adopted the concept, albeit in the last six to seven years. Today, prominent sectors of Nigeria's creative industries- film, music and fashion - are the fastest expanding major markets globally. As at 2016, Nollywood (the Nigerian film industry) was raking in a profit of $\$ 500$ million per annum (PWC, 2016). The music industry, which has gained traction all over Africa and overseas, was worth \$40 million in 2011 and \$47 million in 2015. 
The projection for 2020 is for this figure to reach $\$ 86$ million (PWC, 2016). Also, fashion and design earnings are put at slightly over $¥ 2$ trillion of Nigeria’s rebased GDP (National Bureau of Statistics, 2015). With these impressive figures, the creative industries have been viewed as a sector that could help the Federal government reach its goal of diversifying the nation's economy away from oil exports, making it a stronger force to reckon with on the global stage (National information, communication policy, 2012).

Although the discourse around the monetization of creativity through the creative industries seemed to be a priority, Nigeria's creative industries have not mirrored the level of success recorded by first world economies, many of which have used the creative concept as a launch pad. It should be noted that the term "success", for purposes of this paper, is to be understood to mean "the achieving of the results wanted or hoped for" (Oxford Advanced Learner's Dictionary, 2015). While the reason for this slow progress is beyond the scope of this paper, it is necessary to discuss briefly why Nigeria's creative industries have not achieved the results which the government anticipated. One reason lies in the suggestion that much of the information about the creative industries is not collected in a systematic manner and sometimes the information is dated (The Work Foundation, 2010). This is one of the reasons the British Council in collaboration with local partners carried out a mapping of the Nigerian creative industries to gather empirical data on its dynamics (The Nigerian Creative Economy Report, 2013). One key finding from the study was that creative businesses are excluded from data on the major economic sectors of the Nigerian economy. Today, the industry still grapples with the same issues even in the face of impressive statistics that show great potential for the sector in monetary terms. Therefore, while the Nigerian creative industries sector is large, diverse, dynamic and growing, it lacks formalization, standardization and coordination. It also discovered that much of the problem had to do with the structure of the industry which functions in a disconnected manner as a result of arranging its activities around formal and informal activities. This pattern also plays out in the composition of the creative class used as a case study in this work.

\section{THE CREATIVE CLASS IN NIGERIA'S CREATIVE INDUSTRIES}

\subsection{Who is the creative worker?}

Florida (2002) observes that growth in the creative industries is dependent on the availability of skilled workers, who play a significant role in the creative production process. It is also argued that the creative industry is heavily dependent on the worker. Generally, the creative industries rely on their creative input and their activities are often embedded in the wider economy (Hartley, 2005; Hotho and Champion 2011). The workforce is so important that the Concentric Circles model of the creative industries (first conceptualized by the Work Foundation in 2007) places the creative worker practically at the center, making creative work one of the key components that keeps the system together. The model suggests that the workforce plays a leading role in sustaining the creative economy because workers add value through their creativity, craftsmanship and ingenuity (The Work Foundation, 2007). But one thing hampers creativity is the quality of life experienced by a worker because the latter is directly related to the level of productivity on the job. This in turn has implications for the creative economy in terms of output and earnings.

Creative work can be further classified using the Creative Trident methodology (Higgs, Cunningham \& Bakhshi, 2008). This approach was also adopted by the Queensland University of Technology Centre of Excellence for Creative Industries and Innovation (CCII, 2013) as a blueprint for understanding the dynamics of the various occupations within the creative workforce. It identifies: specialist creatives as those who work directly in the creative industries; support workers as those who offer services to the creative industries; and embedded creatives as those who are creatively occupied, but work outside the creative industries (IBIS World Industry Reports, 2013). However, the present work draws on the seminal work on the creative skills landscape in Nigeria by Tom Fleming (2016) which paints a picture of the current creative industries skills offer in Nigeria. The thrust of the argument is that while there has been investment in creative clusters, there is little evidence of investment in skills and training to feed the clusters and build a sustainable local labour market. Many of the creative workers fall under 'support workers' or 'embedded creatives' categories and for this reason, the story of the creative industries in Nigeria remains one of untapped potential.

\subsection{The Creative Class in Nigeria's Fashion Industry}

One sector of the creative industries where there is seeming success in terms of fusion of both culture and creativity for profit globally is the fashion sector. Fashion is categorized as a part of the design sub-sector of the creative industries (DCMS, 1998), and it is given special attention because of its trade potential. Globally, the fashion industry creates thousands of jobs with 1.9 million people employed in this sector in the United States alone. In terms of income, fashion is ranked as the world's seventh largest economy with an earning potential of about \$2.4 trillion worldwide, and an annual industry growth of 5.5\% (McKinsey, 2016). Ahmed and Berg (2017) refer to it as a global industry with supply and value chains that cut across different countries. The women's wear industry is valued at $\$ 621$ billion; menswear at $\$ 402$ billion; children's wear at a global retail value of $\$ 186$ billion; sports footwear at $\$ 90.4$ billion; and the bridal wear industry is valued at $\$ 57$ billion 
globally (Fashion United, 2016). In the United Kingdom, fashion contributed over \$26 billion to the UK economy in 2009. Today, it accounts for about 4\% of the country's GDP (The British Council, 2017). This success is mirrored in the United States, with the city of New York grossing over $\$ 98$ million from the fashion sector. Similarly, a revenue of over $\$ 32$ billion was generated by the German fashion and textile industry, with Paris - the fashion capital of the world - contributing an estimated \$55 billion to France's economy in 2016.

Nigerian's fashion industry is classified under the clothing and design creative sector. It interfaces with the textile and garment sector as well as several others, pulling their creative/craft workers into its design production process, creating jobs and opening up business opportunities. As at 2012, there were 4,142 creative businesses in Nigeria and $84 \%$ of those employed in such businesses are found in the fashion sector (Dandaura, 2013). In terms of its position in the global fashion world, the Nigerian fashion industry has been described as fashion's new front liner (Jennings, 2011). This growth began in the last decade, when a small but dynamic group of fashion designers inspired a revolution in 2009, by featuring Nigerian designs at New York fashion week arguably the world's most significant fashion event. Since then, the frequency of Nigerian brands on display at international shows and exhibitions has intensified, a sign that Nigerian fashion has caught and sustained the attention of the world. Increasingly, Nigerian designs are no longer seen as mere traditional wear, but outfits that can be incorporated into the wardrobe of various celebrities home and abroad. Many of them are found wearing Nigerian brands crafted and marketed by designers like Tiffany Amber, Deola Sagoe, Lola Faturoti Folake Folarin-Coker, Maki OH, Zizi Cardow, Gogo Majin, Ohimai Atafo, Frank Oshodi, Ade Bakare, Lisa Folawiyo, Soares Anthony and Maufechi. In terms of locations, cities like Lagos - south-west Nigeria - have a high concentration of fashion businesses covering areas like Surulere (90.4\%), Ajeromi (92.6\%) and Isolo (90.2\%) (Dandaura, 2013). Lagos, the former capital of Nigeria also attracts an international audience to view the creativity of Nigerian designers at the Lagos Fashion and Design week (LFDW) and the Guarantee Trust Bank Fashion Week (GTFW) since 2016. Brands like Selfridges, Vivienne Westwood and Browns UK have become frequent buyers, with others like Diesel and Mango coming into retail partnerships with local designers (Offiah, 2017).

Calabar, the Cross-River State capital in south eastern Nigeria has also been perceived as a destination of interest for fashion production in Nigeria, with an influx of creative workers coming into the industry in 2005, following the launch of Carnival Calabar. The carnival - christened 'Africa's biggest street party'- attracts fashion firms, buyers and fashion journalists from across the world, and is aimed at promoting aspects of Nigerian heritage and culture in an economically beneficial way (Amaefula \& Eze-Orji, 2016). The event which is a month-long activity also offers a unique opportunity for Nigeria to showcase culture and creativity. Creative workers in fashion houses and garment factories are heavily involved in this state project, producing costumes that rival those worn at the Rio carnival in Brazil, the Notting Hill carnival in the United Kingdom and Carnival Trinidad (Ministry of Information and Culture, 2014). The 2010 edition of the festival generated over $\$ 7$ million in ten local municipal communities alone (Amalu \& Ajake, 2012). Exports of Nigerian designs are also on the rise, and statistics estimate the total worth of the sector to be slightly over $\$ 2$ trillion. Of this figure, textiles, garments and footwear account for $0.47 \%$ or $\$ 380$ billion of Nigeria’s rebased GDP (National Bureau of Statistics, 2017). With this consciousness, collective calls by industry stakeholders like the Nigerian Economic Summit Group have advocated for increased investment in the creative sector as a means of diversifying the nation's economy (NESG, 2011). However, there appears to be greater attention on the extravaganza of fashion and enterprise than on the people involved in the creative production process. Industry watchers criticize this new direction, which conceptualizes fashion as an intensive money-making business. Krumova (2014) also observes that the industry appears to thrive through the staging of events that involve heavy marketing communication and media hype. The fashion media plays a major role in this regard, with a young generation of writers and bloggers like 'Bella Naija, Arise Live, Access Date and One Nigerian Boy' raising the profile of the industry.

Also, closer scrutiny points to the fact that the apparent progress is purely superficial. Findings from the International Labour Organization (2002) show that a large number of fashion workers in Nigeria operate in the informal economy (It should be noted that the term 'informal economy' for purposes of this paper, is to be understood as a class of workers who are not protected under legal and regulatory frameworks and are characterized by a high degree of vulnerability). The mass of creative workers who make up $60 \%$ of the fashion creative workforce are found in this category. The ILO's findings are at variance with the creative industries concept which attributes the creative industries with the creation of jobs, promoting social inclusion as well as human capital development (UNCTAD, 2010). This situation affects not just the structure of the fashion industry, but the overall output accruable to the sector. Therefore, while there is growth in the industry, systematic even development of the workforce has not been achieved. These issues appear to be unique to the fashion industry in developing countries, because fashion as a creative industry falls squarely in the formal sector in first world countries like the United Kingdom, Australia and Germany. The foregoing offers a number of perspectives from which to understand the creative industries with a specific focus on fashion. The present study however argues 
that the creative industries policy has paid insufficient attention to the experiences of creative workers, many of whom feel isolated, vulnerable and sometimes victimized by the system in which they operate. This study argues that rather than focus on industry debates, more attention should be on the creative worker because accomplishments in the creative economy originate from personal ideas, talent, and craft work. To further appreciate the creative industries, it is necessary to be aware of the dynamics of the creative workforce.

\subsection{The Dynamics of the Creative Workforce}

Fashion workers comprise high end designers as well as talented craftsmen and women like beamers, pattern makers, dress makers, buyers, fashion photographers, designers, graphic artists, hand craft tailors, embroiders, stoners and textile technologists. Primarily they are involved in the production of clothing and other creative pieces which complement various forms of apparel (UNCTAD, 2010). However, each creative occupation group have a specific set of skills. Together, they produce a range of creative products that keep the industry going. Also, there are a number of workers who contribute to the different stages of the production value chain, loosely referred to as the fashion production process (Oduok, 2017). Offiah (2017) identifies two models around which the stages of fashion production are structured in Nigeria. In the first model, fashion designers set up outlets themselves and are responsible for the entire production process. This is the case with fashion houses like Supreme Stiches, Mai Atafo Inspired and Nikki Fashion. In the second model, smaller fashion entrepreneurs set up retail distribution networks which carry selected designs for sale. These include smaller outlets including Mojab, House of Maracci, Master's Touch and Mora Fashions (FDA, 2016).

The present study identifies a third category - the craftsmen and women on the other end of the continuum, who are the recipients of non-formal education programmes and poverty reduction schemes across the 36 States of Nigeria. From this dichotomy it is possible to identify a form of fragmentation which has serious implications not only for the structure of the fashion industry, but the overall output accruable to the sector. Inequalities and exclusions in the current workforce are demonstrated in findings section. Arvidsson et, al. (2010) also identify the dearth of research in the dynamics of the creative workforce and suggest that researchers need to do more empirical studies on the creatives, to gain a better understanding of what their actual working conditions are. An analysis of creative work should therefore include the conditions under which they do their jobs and build their careers. To achieve this, the present study examines groups of workers that cut across workers in the specialist creatives category. These workers are found in the production rooms of fashion houses, garment factories and those who work in small clusters in the cities of Lagos and Calabar. $70 \%$ of them make up the following creative work groups - beamers, pattern makers, dress makers, designers, graphic artists, hand craft tailors, embroiders, stoners and textile technologists. These creative work groups make up the population for this study. While, previous studies on the creative workforce focused on creative occupations (Adebayo, 2013; Oduok, 2017; Brook et al., 2018), this study also examines creative crafts which are rarely conceptualized as core creative jobs in the industry.

\section{METHODOLOGY}

150 respondents were drawn from the two fashion capitals of Nigeria, Lagos and Calabar through purposeful sampling. The main source of data was 150 qualitative interviews conducted in three phases. The first phase comprised interviews with 30 workers including show room managers, supervisors and junior designers found in the executive offices of Supreme Stiches - a leading design house located in Lagos State. The second set of interviews were conducted with 20 crafts entrepreneurs who are graduates of Field of Skills and Dreams (FSD)a fashion training institute chosen because at the time of this study, the company had won several awards for being the top training institute in Lagos State. FSD was also found to be a suitable research site in terms of record keeping and for this reason, a lot of secondary data was gathered from the FSD's employee records. The third set of interviews were conducted with 100 workers found in production room of the Calabar garment factory in Cross River State. The factory has staff strength of 5,000 permanent workers and $60 \%$ of whom are female. The production house is staffed predominantly by tailors and seamstresses who make costumes and school uniforms for a number of primary schools in Calabar as well as military and police uniforms. The interview questions covered a range of issues that focused on the state of creative work in the fashion industry, including: training, income, number of working hours, unions, government funding and policies.

\subsection{Limitations}

It is acknowledged that findings from a sample of workers in these organizations and states alone may not permit a complete picture of reality in the sector. However, it does give insight into what happens on a smaller scale in the industry. Further research and mapping are required across the other States of the Nigerian federation where the fashion industry is gaining ground including Enugu, Abuja and Anambra. It is however important to state that while the Nigerian fashion industry prides itself for employing a variety of creative hands and minds, there is a need to report the differences in terms of service across various classes of workers. This study addresses this 
gap.

\section{ANALYSIS AND DISCUSSION}

\subsection{The Working Conditions of Fashion Workers in Nigeria}

Findings from the data are coded into the following categories: Training, Income, Working hours, Regulation and Government Funding.

\subsubsection{Formal Training Inequalities}

Six managers at Supreme Stitches are skilled designers who obtained formal training from a number of European academic institutions and they possess degrees from countries such as the United Kingdom, Switzerland and Scotland. Four of them attended the Pratt Institute in Brooklyn, New York that trains graphic artists, fashion designers and other creative professionals. The other two attended the Fashion Institute of Technology (FIT) Manhattan also in New York and the Massachusetts Institute of Technology. Other respondents had studied fashion and textile and design at the Yaba College of Technology in Lagos, Nigeria. Respondents were of the view that the international exposure and training received was the biggest bargaining chip in terms of remuneration and position at the fashion house. Among the supervisors interviewed, six had not attended any formal school of fashion outside the country but had honed their skills at vocational training institutes and educational centers that offer fashion courses and crafts training. The most popular institute among the respondents was the Field of Skills and Dreams (FSD) in Lagos. They undertook training in tailoring, and crafts studies like bead/jewelry making and shoe/handbag design. The enrollment statistics from vocational institutes like the FSD are crucial because the figures show the number of creative workers who opt for vocational skills in the absence of training from world class fashion institutes. Table one shows the figure for 2015, while Table two shows that the total figure doubled by 2016.

Table 1 - The rate of enrollment and graduation of fashion workers based on FSD records from JanuaryDecember 2016

\begin{tabular}{|c|c|c|c|c|c|c|c|}
\hline & $\begin{array}{l}\text { BASIC } \\
\text { TRAINING }\end{array}$ & SEX & $\begin{array}{l}\text { ADVANCED } \\
\text { TRAINING }\end{array}$ & SEX & & & \\
\hline & & $\mathrm{M} / \mathrm{F}$ & & $\mathrm{M} / \mathrm{F}$ & EMPLOYED & UNKNC & $\begin{array}{l}\mathrm{N} \mid \text { TOTAL } \\
\text { GRADUATED }\end{array}$ \\
\hline Sewing & 5 & $1 / 4$ & 32 & $7 / 27$ & 33 & 4 & \\
\hline $\begin{array}{c}\text { Soft } \\
\text { Furnishing }\end{array}$ & 19 & $6 / 13$ & - & - & 16 & 3 & \\
\hline $\begin{array}{c}\text { Ankara } \\
\text { Accessory }\end{array}$ & 21 & $7 / 14$ & - & - & 18 & 3 & 77 \\
\hline
\end{tabular}

Source: Field of Skills and Dreams VTE Academy Records, 2016

Table 2 - The rate of enrollment and graduation of fashion workers based on FSD records from JanuaryDecember 2016

\begin{tabular}{|c|c|c|c|c|c|c|c|}
\hline & $\begin{array}{l}\text { BASIC } \\
\text { TRAINING }\end{array}$ & SEX & $\begin{array}{l}\text { ADVANCED } \\
\text { TRAINING }\end{array}$ & SEX & & & \\
\hline & & $\mathrm{M} / \mathrm{F}$ & & $\mathrm{M} / \mathrm{F}$ & EMPLOYED & UNKNOWN & $\begin{array}{l}\text { TOTAL } \\
\text { GRADUATED }\end{array}$ \\
\hline Sewing & 20 & $0 / 20$ & 51 & $22 / 39$ & 57 & 14 & \\
\hline $\begin{array}{l}\text { Soft } \\
\text { Furnishing }\end{array}$ & 27 & $10 / 17$ & - & - & 25 & 12 & \\
\hline $\begin{array}{l}\text { Ankara } \\
\text { Accessory }\end{array}$ & 25 & $8 / 17$ & - & - & 22 & 3 & 133 \\
\hline
\end{tabular}

Source: Field of Skills and Dreams VTE Academy Records, 2016

The jump in the figures shows that there are many more creative workers who do not have the requisite formal training in the fashion industry than those who do. Statistics from the National Directorate of Employment (2017) also justify a spike in apprenticeships by establishing a link between the acquisition of vocational skills like fashion design, tailoring, soap making, catering, hair dressing, beads making, hats making and a significant reduction of poverty among young adults who participated on skills acquisition programmes.

Respondents were also of the view that lack of skilled technical hands as a result of poor educational qualifications are a major reason some workers fail to rise in the system. Mr. Black said, "I did a six-month 
advanced training course in fashion and design at the FSD to improve my skills. But there are still some aspects of design they will not trust me to handle. I can do it, but my degree is not from the right place, if you know what I mean". During the course of the interviews, it emerged that there is another group of workers that fall into a different category from the trainees above. This group of workers graduate and set up small businesses of their own. Some of them work in clusters around the city of Lagos including: stoners, embroiders, hand-craft tailors and beaders. This study christens such workers 'craft entrepreneurs' because they not only acquire craft skills with which to set up their businesses, but they are also employers and trainers of other craftsmen through apprenticeships. Data from the FSD shows that about $100 \mathrm{craft}$ entrepreneurs graduate every year. Table three reflects some of this data.

Fig. 1. - The number of craft entrepreneurs introduced into the fashion industry by the FSD over a four-year period

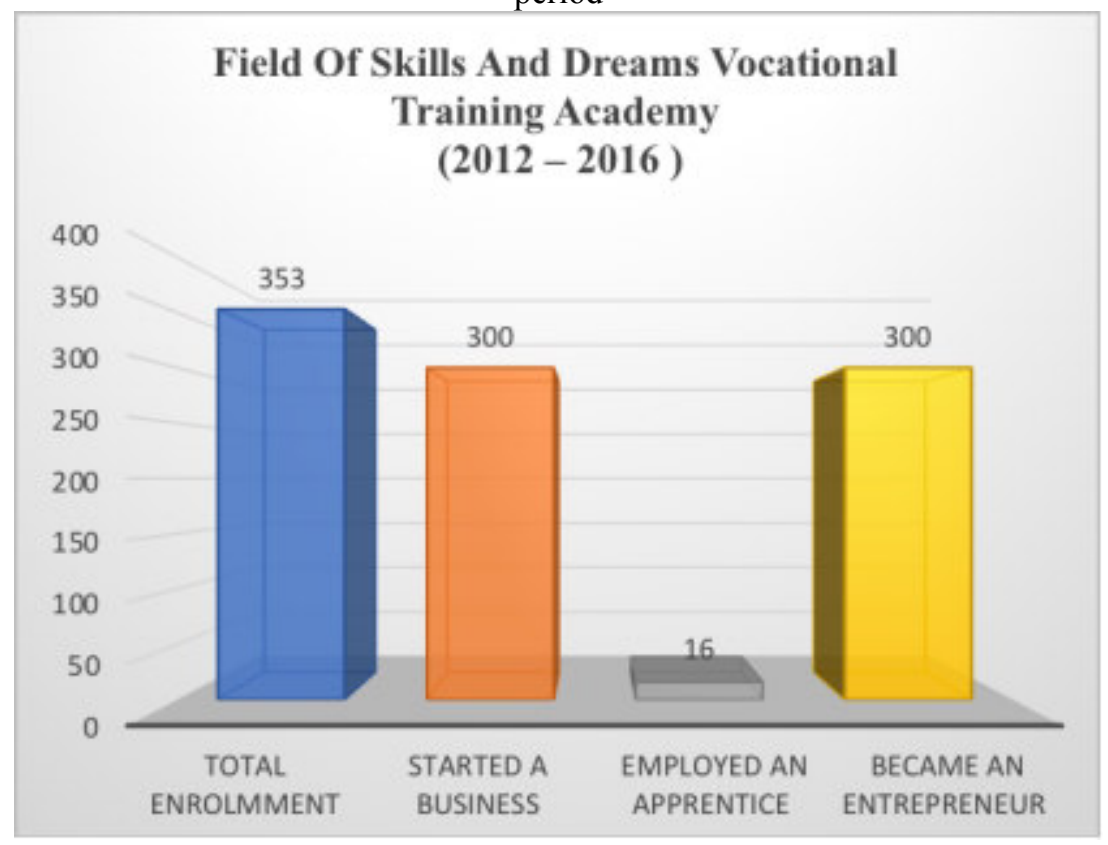

Source: Field of Skills and Dreams VTE Academy Records, 2016

All respondents in the crafts entrepreneur category complained about doing business under harsh economic conditions including having to contend with unstable power supply and the use of outdated machines/equipment. $70 \%$ of workers found in the production room of the Calabar garment factory had formal education but not at an advanced level. The highest level of education was the Senior School Certificate Examination (SSCE). Their responses show that many of them have been working in design for years by learning on the job. Respondents said they enjoyed a form of government financial intervention, as 300 of them were placed on a subsidized technical and professional training tailoring programme. At the end of the training, beneficiaries train other members of the workforce. 20 of the respondents interviewed for this were beneficiaries of the government training scheme. Respondent X said, "I had no money and no skills when my husband died. Now I am earning money because of what I learnt at the factory".

\subsubsection{Income: Pay inequalities}

While the lead designers and top executives at Supreme Stiches would not reveal their income, the middle managers and some supervisors said their pay was satisfactory with some admitting to a monthly income of $\$ 1$ million to $\$ 1.2$ million. The figure excludes medical insurance, housing allowance and other fringe benefits. It was a slightly different story for supervisors who are found to be paid on a contract basis. Respondent Y said, "We are given a basic salary of $\$ 300,000$ (three hundred thousand naira) and then we earn a commission based on the number of clients we bring in per month. Our income is not fixed because we have to hustle a lot". Responses were not the same for the craft entrepreneurs who operate small businesses of their own. Many of them complained about the high cost of doing business which affects their profit negatively. One respondent spoke about spending $\$ 150,000$ (one hundred and fifty thousand naira) monthly to power a small generator because of lack of constant power supply in his area of operation. When asked about his overall profit, the same respondent spoke of making $\$ 300,000$ (three hundred thousand naira) a month. The books showed that the unit cost of stoning one outfit is $\$ 7,000$ (seven thousand naira) and customers were charged $\$ 10,000$ (ten thousand naira). From the findings, almost half the revenue is spent on fuel. Findings also show a disparity in income between craft entrepreneurs and their colleagues in design houses. One respondent spoke of earning $\$ 500,000$ (five hundred thousand naira) a month. Others make about $75 \%$ more than crafts men and women. The disparity 
in income shows that there is uneven development in the sector. Table 4 - below shows the average amount of income accruable to crafts entrepreneurs

Table 3 - Average amount of income accruable to crafts entrepreneurs:

\begin{tabular}{|l|l|l|}
\hline FSD ALUMNI & AVERAGE MONTHLY INCOME (Naira) & BUSINESS LOCATION \\
\hline Student A & 180,000 & Maryland \\
\hline Student B & 150,000 & Egbeda \\
\hline Student C & $175,000-350,000$ & Surulere \\
\hline Student D & $195,000-350,000$ & Ikeja \\
\hline Student E & $225,000-300,000$ & Gbagada \\
\hline Student F & $165,000-250,000$ & Ogba \\
\hline Student G & $185,000-250,000$ & Ojodu \\
\hline Student H & $200,000-300,000$ & Ajah \\
\hline Student I & $200,000-300,000$ & Magodo \\
\hline Student J & $250,000-400,000$ & Lekki \\
\hline
\end{tabular}

Source: FSD, Alumni 2015/2016 Graduates

It should be noted that the income generated by these groups are not captured in the literature or official data available on the fashion industry. The mapping of this revenue accruable to the informal sector is therefore important if the real contribution of the industry to the creative economy is to be determined. For respondents in the Calabar factory, wages are paid weekly. One respondent said that the average pay for a daily 10-hour shift is $\$ 2,000$ (two thousand naira). This comes to $\$ 10,000$ (ten thousand naira) weekly and $\$ 40,000$ (forty thousand naira) monthly. The only benefits received according to one respondent is a free bus ride to work. $70 \%$ of the respondents were unhappy about their wages in light of Nigeria's present economic realities, but some were grateful to be employed. All the responses indicated that the amount of income accruable to the various classes of workers in the industry differs. Therefore, while the fashion industry is celebrated for bringing in big business, there appears to be an uneven rate of economic growth among the members of its workforce.

\subsubsection{Working Hours Inequalities}

Respondents working in big design houses complained about working very long hours averaging 12 hours a day (including weekends and public holidays). A number of supervisors also complained of working overtime without receiving payment for the extra hours, particularly during fashion shows and special events. There were also no official lunch breaks and little opportunity for shift work. However, the crafts entrepreneurs had a different reason for keeping long hours. Mr. B said, "One of the reasons we have to work through the night is epileptic power supply. We tend to have electricity at night, so I have to work at that time to meet up with my clients' demands". Samson said, "I have no closing time. I close when I finish sewing and that is because we do not have electricity to work during regular working hours".

Workers at the Calabar factory did not complain about the length of time spent on shifts, but there were concerns about exposure to industrial machines for long hours without the requisite safety equipment. Monica, a stoning machine operator said, "I don't have gloves and face mask to protect my eyes and face from the heat of this machine. I have been complaining, but nobody cares". There were also complaints from those who are heavily engaged during the Calabar carnival. Jack said, "We do not rest throughout the period, and most times we only collect our normal pay, nothing extra". From the responses, it emerged that some creative workers are vulnerable and often accept unpaid or low-paid work just to be able to acquire skills, competency and experience.

\subsubsection{Regulation: The Role of Unions}

One of the unions associated with the fashion industry is the National Union of Textile Garment and Tailoring Workers of Nigeria (NUTGTWN), an affiliate of the Nigeria Labour Congress. It was formally registered in 1978 and established to act as an advocate for creative workers like textile and garment makers, to protect them from exploitation from employers in the public or private sector (NLC, 2017). In the 1980's, the union had 250,000 memberships comprising textile workers, tailors, fashion designers and buyers. By 1997, the union had 
20,000 members. This drastic drop in union membership has been linked to the closure of many textile factories across the country (Muhammad, 2011). The crisis in the textile industry is closely related to the poor run of the manufacturing sector in the last two decades.

While the manufacturing sector once accounted for 8\% of Nigeria's GDP in the 1990's (UNCTAD, 1997), it suffered severe setbacks for reasons which are both local and international. Following the signing of trade agreements between Nigeria and other nations owing to the globalization trend, the Nigerian market was flooded with fabrics and materials that were regarded as better in quality because they were made by superior machinery outside the nation's shores (Waters, 1995). This seeming misconception led tailors and dress makers to reduce patronage of Nigerian-made fabrics, thereby eroding the local advantage once experienced in textile production. The crisis that ensued led to the collapse of several textile factories particularly in Kano State, where the number reduced from 40 to 10 between 1980 and 2003 (Muhammad, 2010). With the closure of factories came heavy job losses for creative workers, the worst of which was experienced in 2007, with 5,515 workers sacked after two major factories were shut down in Kaduna and Lagos. Many workers remain disenchanted with the union, leading to a reduction in membership numbers. When participants in this study were asked if the unions played a role in terms of improving their working conditions, their responses were in the negative. All the respondents said the unions did not play any role in countering the problems of low pay, long working hours and cases of exploitation.

\subsubsection{Regulation: Industry Associations}

The Fashion Designers Association of Nigeria (FADAN) was incorporated in 1989 by the Federal Ministry of Trade and Corporate Affairs at the time to duly represent the interests of fashion designers all over the country and influence clear policy direction in the industry. The designers at Supreme Stiches were all happy with the activities of FADAN except its hard stance of bi-annual inspection of their equipment, staff and working environment. Some were of the view that the process could give room for corruption, but such responses were in the minority. All the craft entrepreneurs frowned on the fact that they do not receive any form of financial support from FADAN or any other formal agency. One respondent said, "FADAN does not welcome small people like us. They get together and make money, while we continue to struggle here". Respondents believe that FADAN neither functions as a regulatory body, nor does it address the issue of funding for its constituents and as a result, many have lost faith in the organization. From the responses, one of its biggest criticisms of FADAN is that majority of its members belong to a rich designers' 'cult'. Others say the association prioritizes the problems and challenges of a select few to the detriment of all others in the sector. None of the respondents at the Calabar factory had heard of FADAN and they were unaware of any other association representing the interests of fashion workers. However, a past president of FADAN was of the opinion that many individuals enter the industry without the formal requisite training and for this reason they are unwilling to get the accreditation needed to be legally recognized as members of FADAN.

\subsubsection{Government policy and funding}

There was a general feeling that the federal government's policies on importation have hampered the growth and development of the fashion industry. Designers frowned on the high cost of importation of fabrics, embroidery machines, sewing machine threads, lining, etc. Respondent B says, "When the prices of imported materials go up, it affects us drastically". However, the responses from crafts entrepreneurs were mixed. Some were unhappy about the absence of government funding, as well as arbitrary economic policies that hamper business. Respondent F said, "As a tailor, I trained myself. I work very hard with no support from the government at all". Others praised the State Government (in Lagos) for its employment trust initiative under the Lagos State Employment Trust Fund (LSETF, 2016). The fund was set up to inspire the creative and innovative energies of all Lagos entrepreneurs by making funds available through a loan worth $\$ 25$ million. However, three respondents were highly critical of the scheme for reasons ranging from a cumbersome application process and stringent requirements, to bureaucracy regarding the processing of the loan through the banks. These findings suggest that policy makers have not paid sufficient attention to the welfare of creative workers, many of whom feel let down by the system.

\section{CONCLUSION}

The Nigerian fashion industry in the last decade has been viewed as both a cultural and creative enterprise while the fashion production process can be likened to a live stage production with a large cast. Although there are many actors, a lot of activity goes on behind the scenes and many times, all the creative hands and minds at work that drive the process are not seen. Over $60 \%$ of such workers are not found on the world's biggest fashion stages but are mostly behind the scenes tucked away in the nation's informal sector. The paucity of research on this group of creative workers means severe under-representation in official data collections. One of the aims of this study was to foreground the important link between creative labour and growth in the creative economy. It suggests that investing in creative workers - essential components of the 'creative core'- could open up the economic opportunities needed to attract foreign direct investment to Nigeria. Therefore, researchers and policy 
makers may need to seriously consider the dynamics of the entire fashion labour force whose creativity and craft produces the cultural commodities that are celebrated for their earning potential. A key contribution of the paper is that it is necessary to understand the different strata of creative workers who negotiate the peculiarities of the Nigerian creative space. With a population of over 180 million people, talent is the ready raw material for the creative economy in Nigeria. But talent can only go so far without the right skills. The creative industries will not grow to its full potential if the nation does not give talent every opportunity to develop the skills which will enable it to compete in an increasingly global marketplace.

\section{RECOMMENDATIONS}

This study shows that the fashion workforce is characterized by high end designers, fashion entrepreneurs, craft entrepreneurs and the creative mass - each working in their own circles of influence and adding value to the creative economy in their own way. But the social class mix shows a diversity of life experiences and backgrounds represented in the sector, which will influence the creative-cultural product that is produced and commissioned. One recommendation is for the government to invest in a thorough mapping of the fashion workforce to give direction to policy makers and planners. Although a mapping work group ran a pilot study for the Nigerian creative industries as a whole (Dandaura, 2012), the objective among other things was to gather data to determine the general character, size and contributions of the creative industries to the Nigerian economy. However, it is necessary to hone the research area further by making the workers the principal subject of study. This is because their conditions of service to a large extent determines their level of productivity.

While there are a number of fashion academies in the country, none are up to the standard of schools of fashion in the West. Majority of them remain at the level of vocational institutes and colleges, and this affects the quality of jobs workers are able to get. For this reason, the creative workforce is heavily fragmented with an uneven development that has a trickledown effect in terms of revenue accruable to the industry. Findings show that most of the industry value is captured by a small percentage of players, with the top 20 percent giving the impression of a rapidly thriving sector for all cadres of workers. In reality, prominent designers who have been exposed to formal training and a robust business background are mostly in the lime light and better paid. These are the front row architects of fashion who are generally used as a yardstick to measure the impact of the fashion industry on the wider economy. Workers from the other side of the spectrum who possess vocational skills are easily discriminated against, and those who start small businesses have little financial support from the government. However, their earnings are significant enough to be a valuable contribution to the creative economy. It can then be argued that the true worth of the fashion industry is unknown because the economic contribution of a large portion of the creative workforce has not been systematically captured by national statistics. If the contribution of a key chunk of the workforce is largely unknown, then the fashion industry can only make a 'guestimate' of its contribution to the country's GDP.

This study also recommends a sustained and targeted government intervention in terms of research funding, grants and financial aid to support fashion workers. Funding is still a major issue in the fashion sector as much of the financial assistance from the Federal Government is not guided by a specific strategy or policy. Rather than random cash injection into a few sectors, the industry could benefit from the establishment of a ministry of fashion that has the capacity to address the changing needs of the various categories of workers in the creative workforce. Furthermore, the dearth of skilled workers in the industry remains a challenge. In this regard, the government in collaboration with the private sector could establish a national fashion academy to promote world class formal craft and skills training in fashion design, retail and other aspects of fashion production. While there are unions and associations set up to influence public policy with respect to the fashion workers, they have not yet been successful at responding to the needs of their constituents. Unions should therefore take a more active role in protecting all categories of fashion workers from exploitation and poor working conditions. In this regard, policies and regulations should be followed up to ensure that they explicitly favour the workers. The fashion sector is also heavily dependent on critical infrastructure like power. An improvement in this area could boost the commercialization of creative talent in order to reap its rewards.

Another key recommendation is for the Nigerian governments at all levels to create conducive conditions for the creative industries to thrive using a combination of regulation and regular financial interventions. They should also provide tax incentives for creative entrepreneurs to discourage them from tax evasion and the inaccurate declaration of incomes. There is also a need for increased research funding for regular mapping of the fashion sector and its actors, to chart its progress as well as its true contribution to the wider economy. Future research directions should also include more empirical studies on the fragile structure of Nigeria's creative industries and the manner in which its participants operate.

\section{References}

Adebayo, O. (2013). Embarking on entrepreneurial activity in textile and clothing industry is the only way for economic growth in the sector. British Journal of Arts and Social Sciences, 12(1), 78 - 88. 
Adorno, T., \& Horkheimer, M. (1994). The culture industry: Enlightenment as mass deception.

Retrieved September 5, 2017, from http://docplayer.net/20698421-Theodor-adorno-and-max-horkheimer-theculture-industry-enlightenment-as-mass-deception-1944.html

Adorno, T., \& Rabinbach, A, (1975). Culture industry reconsidered. New German Critique, (6), 12-19.

Amaefula, R., \& Eze-Orji, B. (2016). Costuming for African values: A reassessment of in Calabar carnival. Retrieved August 6, 2017, from https://www.researchgate.net/publication/305627663_Costuming_for_African_values_a_reassessment_of_ un-African ideals in_Calabar_carnival

Amalu, T. \& Ajake, A. (2012). An assessment of the influence of Calabar carnival on the economy of the residents of Calabar metropolis, Cross River State, Nigeria. Geography \& Environmental Geo-Sciences, 12(10), 65-74.

Amed, I., \& Berg, A. (2017). The state of fashion - The business of fashion and McKinsey \& Company. Retrieved April 22, 2017, from http://www.mckinsey.com/industries/retail/our-insights/the-state-of-fashion

Arvidsson, A., Malossi, G., \& Naro, S. (2010). Passionate work? Labor conditions in Italian fashion. Journal for Cultural Research. Retrieved January 10, 2017, from https://zoescope.files.wordpress.com/2013/02/passionatework.pdf

Brook, O., O’Brien, D., \& Taylor, M. (2018). Panic! Social class, taste and inequalities in the creative industries Retrieved January 2, 2019, from www.createlondon.org/event/panic2018/

Creative Industries Innovation Centre final Report (2013). Valuing Australia'screative industries. Retrieved May 5, 2017, from http://www.sgsep.com.au/assets/Valuing-Australias-Creative-Industries-FinalReport.pdf

Dandaura, E. (2013). Nigerian creative economy report. Mapping of Nigeria creative industries: Report of Lagos pilot study. Retrieved February 12, 2017, from https://www.researchgate.net/publication/290997707_Nigerian_Creative_Economy_Report

Dai, J., Zhoul, S., Keane, M., and Huang, Q. (2013). The mobility of the creative class and city attractiveness: A case study of Chinese animation workers. Eurasian Geography and Economics, 53(5), 649-670.

Department for Culture Media and Sport (1998). Creative industries mapping document.

London: DCMS

Fashion United (2016). Global fashion industry statistics - International apparel.

Retrieved June 21, 2017, from https://fashionunited.com/global-fashion-industry-statistics

Field of Skills and Dreams (2016). Academy Report on state of fashion entrepreneurship. Retrieved March 9, 2016, from http://www.fieldofskillsanddreams.com

Flew, T. (2002). Beyond adhockery: Defining creative industries, presented at the second International

Conference on Cultural Policy Research, Te Papa, Wellington, New Zealand.

Fuller, T., Warren, L., \& Norman, J. (2009). Creative methodologies for understanding a creative industry. Retrieved February 17, 2017, from http://www.isbe.org.uk/content/assets/BP09-TedFull

Galloway, S., \& Dunlop, S. (2007). A critique of definitions of the cultural and creative industries in public policy. International Journal of Cultural Policy, 13(1), 17-31.

Hesmondhalgh, D., \& Baker, S. (2010). A very complicated version of freedom: Conditions and experiences of creative labour in three cultural industries. Poetics, 38(1), 4-20.

Hesmondhalgh, D., \& Baker, S. (2011). Creative labour: Media work in three cultural industries. London: Routledge.

Howkins, J. (2001). The creative economy - How people make money from ideas.

London: Penguin Global.

International Labour Organization (2002). Decent work and the informal economy report.

Retrieved July 8, 2017, from http://www.ilo.org/public/english/standards/relm/ilc/ilc90/pdf/rep-vi.pdf

Jeffcut, P., \& Pratt, A. (2002). Managing creativity in the cultural industries. London: Blackwell.

Jennings, H. (2011). New African Fashion. Munchen: Prestel.

Krumova, K. (2014). The African fashion industry revolution. Retrieved

March 19, 2017, from http://printarchive.epochtimes.com/a1/en/uk/nnn/2014/05-May/14/003_News.pdf

Langevang, T. (2016). Fashioning the future: Entrepreneuring in Africa's emerging fashion

industry. $\quad$ Retrieved April $2016, \quad 20, \quad$ from http://fashionomicsafrica.org/_storage/3421fcaa2398842faaa05674825a3d00c1419a921467967929.pdf

Lloyd, B. (2014). The sleeping giant: Nigeria's flourishing fashion industry.

Retrieved June 7, 2016, from https://www.notjustalabel.com/editorial/sleeping-giant-nigerias-flourishingfashion-industry

Makinde, D., Fajuyigbe, M., \& Ajiboye, O. (2015). Nigerian textile industry: A tool for actualizing economic stability and national development. European Journal of Business and Social Sciences, 4(8), 331 - 344.

Muhammad, M. (2011). Globalization crisis and national security: A reflection on Nigeria textile industry. 
Jorind, 9(1), 1596-8308.

National Bureau of Statistics (2015). Retrieved March 20, 2016, from http://nigerianstat.gov.ng/report/559

Nigeria Labour Congress Report (2017). Retrieved March 4, 2016, from http://www.nlcng.org/rattawu.php Nigerian Economic Summit Group Report (2011).

$\begin{array}{llll}\text { Retrieved } & \text { April } & \text { 19, } & \text { 2016, }\end{array}$ http://www.nigerianeconomicsummit.org/NES\%20SUMMIT/images/Resources/Nov\%2012/NES\%20Nove mber\%202011.pdf

O'Connor, J. (2010). The definition of cultural industries. Retrieved February 20, 2017 from http://www.pedrobendassolli.com/pesquisa/icc1.pdf

Oduok, U. (2017). The urgency of now: putting Nigeria's fashion industry on the global map. Ladybrille. Retrieved June 15, 2016, from http://ladybrillemag.com/th e-urgency-of-now-putting-nigerias-fashionindustry-on-the-glo...

Offiah, C. (2017). Globalization and the culture/creative industries: An assessment of Nigeria's position in the global space. Journal of Humanities and Social Science, 22(1), 11-23.

Peter Higgs, P., Cunningham, S., \& Bakhshi, H. (2008). Beyond the creative industries: Mapping the creative economy in the United Kingdom. London: Nesta.

Smith, C. (1998) Creative Britain. London: Faber \& Faber.

The British Council (2017). Retrieved March 5, 2018,from https://www.britishcouncil.org/organisation/facts/programmes-and-initiatives/great-campaign

The Work Foundation. (2007). Staying ahead: The economic performance of the UK's creative industries. The Work Foundation.

Thompson, P., Parker, R., \& Cox, S. (2015). Interrogating creative theory and creative work: Inside the games studio. Sage Journals, 50 (2), 1-33.

UNCTAD (2010). Creative economy report. Retrieved from unctad.org/en/Docs/ditctab20103.

Waters, M. (1995). Globalization. London: Routledge.

\section{Biography}

Ijeoma N. Onyeator is a doctoral student in the School of Media and Communication, Pan-Atlantic University. She was born in Nairobi, Kenya in 1976. She holds an M.A. in Media Communication and Technology from Brunel University Uxbridge, United Kingdom (2003); and a BSc. in Mass Communication from the University of Lagos, Nigeria (1999). Ijeoma became a member of the Association of Communication Scholars and Professionals of Nigeria in 2013. She is also a member of the International Association for Media and Communication Research. She received certification from the Birmingham City University for the Research Leadership Exchange Programme in 2017. Her main research interests include New Media, Alternative News Sources, Citizens Journalism, Cultural Studies and Media Philosophy. She has worked as a media practitioner and journalist for15 years. 